\title{
A Road to Circular Economy: Mindful Consumption
}

\author{
Chainarong Khaw-ngern ${ }^{1}$, Phramaha Wattana Khamken ${ }^{2}$, Shayaniss Kono ${ }^{3}$, Kannikar Khaw-ngern ${ }^{4}$ \\ ${ }^{1}$ Faculty of Humanities, Mahachulalongkornrajavidyalaya University, \\ ${ }^{2}$ Palisuksa Buddhagosa Campus, Mahachulalongkornrajavidyalaya University, \\ ${ }^{3}$ Faculty of Social Sciences, Srinakharinwirot University, \\ ${ }^{4}$ Faculty of Buddhism, Mahachulalongkornrajavidyalaya University \\ 1 chainarong.kha@mcu.ac.th, ${ }^{2}$ Wattanakhamken@gmail.com, ${ }^{3}$ shayaniss@g.swu.ac.th, ${ }^{4}$ kannikar.khaw@gmail.com
}

\begin{abstract}
With higher level of the ecological crisis and the impacts of climate change becoming more and more visible every year, there is an urgent need to search for ways to render our society more sustainable. The purpose of this article is to study the influence of mindful consumption on the transition towards circular economy. Documentary study and literature review were used for data collection. The problems of irrational consumption were examined, circular economy principles were investigated, and explore how right mindfulness effects consumer's behaviors in the consumption process and how it influences the business sector towards circular economy. Results showed that right mindfulness, when applied to an individual's consumption behaviors, it can promote individuals' awareness of waste problems, resource depletion, pollution, environmental degradation and climate change when they make their decision on purchasing. Thus, their consumption process develops in more sustainable way which contributes to resources conservation and environmental sustainability. As a result, it will influence business sector to make a transition towards circular economy; reducing raw material extraction, designing and manufacturing more sustainable/eco-friendly products, and using more recycle materials. Circular economy concept is a great move towards environmental sustainability. Consumers play an important role in the economic system of a nation. If there is no consumers' effective demand, the producers would have no motivation to produce and sell to consumers. To move forwards on the path towards circular economy, consumers are required to make their choice with mindfulness.
\end{abstract}

Keywords

Right Mindfulness, Irrational Consumption, Mindful Consumption, Circular Economy Concept

Article Received: 10 August 2020, Revised: 25 October 2020, Accepted: 18 November 2020

\section{Introduction}

Today's financial and environmental crisis is a sign which something is fundamentally wrong with our economic system. However, the global economic reforms we have seen in recent years whether they are conservative, leftist, or green have been unable to change the destructive course of our economy. Thus, a systematic change is urgently required. The power of the corporation needs to be transformed into the power of cooperation, and the decentralized power of economic democracy should be taking place. Since the economic and environmental problems are all interconnected, the main causes of the problems need to be analyzed to find comprehensive solution. The solution should offer a resilient and sustainable system which is truly revolutionary and establish a balanced economy while saving our rapidly deteriorating ecosystem. It needs to understand human nature including his/her behavior, motives, and meaning as the fundamental elements. Mindful consumption is the application of mindfulness when consumers make their choices. It is concerning their thought and behavior with caring for themselves, communities, and environment which is the goal of circular economy.

The global population will continue to grow, the middle class is set to top 5 billion by 2030, and almost 10 billion people will be living on Earth by 2050 [1]. The effects of excessive consumption are already seen. Economic losses related to extreme weather have increased by $86 \%$ to $\$ 129$ billion over the last 10 years, even basic resources like water are under threat [2]. By 2030, the global population is projected to need $40 \%$ more water than the planet can sustainably supply. Alternatives, however, exist and we only need to look into nature to be inspired and consider the resilience to make the ecosystems better in which the seasons are perfectly harmonized with the lifecycle of all species.

\section{Irrational Consumption}

Consumption has been defined by many researchers from the field of consumption studies that it is a complex process embedded in social, economic, cultural and material systems [3]. It is defined as a process in which consumers engage in possession and appreciation of goods, services, performances, information or ambience over which the consumer has some degree of discretion [4]. To provide a more inclusive definition that demonstrated the processes that objects exit people's lives, Evans [5] suggested three more steps including devaluation, divestment and disposal. Then, consumption consists of six phases. The first phase is acquisition, the process that consumers obtain the objects to be consumed. Second, the use stage which is about physical deterioration of products or embedding acquired objects in everyday life. Third, the appreciation stage occurs when people value such objects in their domestic environment. Devaluation happens when such objects lose their meaning and therefore importance for the consumer. Then, the acquired objects are divested of the consumer's domestic realm. This is the end of the use stage of consumption and moves to the disposal stage which could come in many 
forms, e.g. by keeping them in a storage room or throwing them in the waste bin.

Irrational consumption, decision making based on feelings rather fact, can be considered as one of the major causes of resource depletion, pollution, environmental degradation and climate change and as barriers for sustainable development. When buying things, most consumers make their decision by convenience packaging rather than ecofriendly ones. Many others prefer single use packaging and containers to reusable containers as they feel inconvenient to carry them. In 2008, our global plastic consumption worldwide has been estimated at 260 million tons, and, according to a 2019 ABC Science report by Nick Kilvert, "On average, we each use 53 kilograms of plastic a year and generate a collective total of more than 300 million tonnes of plastic waste. By 2030, this is predicted to double."

Food production and consumption have remarkable negative environmental effects, in particular food waste. Food waste occurs throughout the entire food system, but households make the largest contribution. This happens because lots of consumers make their food choices from its looks rather than its quality, and from its discount if buying two, or in bulk rather than buying in needed quantity. Such food choices cause food leftover all of which ends up as waste. Across global food systems, food loss and waste (FLW) is a global issue challenging the food security, food safety, the economy, and environmental sustainability. There is no accurate estimates of the level of FLW available, but studies indicate that it is about 30 percent of all food around the world [6]. This amounts to 1.3 billion tonnes per year. FLW indicates the wastage of resources, including the land, water, labor, and energy which are used to produce food [7].

Electrical and electronic products (E-products) have become one of the most focus areas that challenge the resource sustainability due to increasing demand, the use of important resource, and the challenges in E-waste management. Ewaste amount is rapidly increasing around the world and it is expected to be double by 2045 [8]. E-waste is also a combination of valuable resources and toxic substances that requires careful management. E-products have evolved to become complex and found everywhere in everyday lives but e-waste collection and management systems have not caught up - mostly failing to ensure proper handling of ewaste. This can cause potentiality of resource losses and negative impacts on environment as well as human health [9].

Currently, lots of consumers frequently replace their functional electronic/electric equipment while it is still operational due to the updated features and designs. They possess extra equipment/gadgets more than what they really need. Many consumers do not think of the lifespan of the products before making decision while some never think of repairing their equipment. Such behaviors can be considered as irresponsible consumption which causes more and more waste in the e-waste stream. On average, the total weight (excluding photovoltaic panels) of global Electrical and Electronic Equipment (EEE) consumption increases annually by 2.5 million metric tons (Mt). In 2019, the world generated a striking $53.6 \mathrm{Mt}$ of e-waste, an average of $7.3 \mathrm{~kg}$ per capita [10].

It is obvious that irrational consumption behaviors can be one of the major causes of the huge waste stream in our societies. On the contrary, responsible consumption, the consumption with awareness of waste problems, resource depletion, pollution, and environment degradation, in other words, the consumption with mindfulness can alleviate such problems and strengthen sustainability for our world. "Each and every one of us must do our part in creating a better world, for though the small choices we make each day what we buy, what we eat, what we wear - may seem insignificant, the cumulative effect of billions of people making ethical choices, will start to heal the natural world", Dr. Jane Goodall.

\section{Mindful Consumption}

In Buddhism, there are many teachings regarding the middle way, the right amount, knowing moderation and all these terms may be considered as synonyms for the idea of balance or equilibrium [11]. The right amount in Buddhism also means not harming oneself and others. This important principle is the basic criterion of right action for all human activity not only in relation to consumption. It implies that 'not harming others' can apply to human beings, to all that lives, and to all ecosystems [12].

From a Buddhist perspective, economic principles are related to the three interconnected aspects of human existence: human beings, nature (ecosystems), and society (with the meaning of the word nature used in the sense of ecosystems). Buddhist economics is the causal process of those three aspects in which they do not harm each other, but work together in a harmonious way and support each other. Economic activity takes place without causing harm or decreasing quality of life of oneself, but making it better. At the same time, it does not violate or damaging society and environment [13].

In Buddhism, right mindfulness is an individual's constant awareness of his body, feeling, and thoughts. It is one of the most important factors of the Noble Eightfold Path as it can direct one to choose the activities that lead to environmental conservation. When people do activities with the right mindfulness, which are simple and easy to adopt, it will lead to a comprehensive potential for environmental conservation. Transition to a process of transformation of current systems of unsustainable production and consumption to sustainable ones, one needs to be thoughtful about what one is buying and choosing a sustainable option wherever possible. Consumers can start with carrying a reusable bag, refusing single-use plastic containers and packages, and recycling plastic bottles.

Right consumption, consumption with right mindfulness, is a comprehensive term as it includes environmental-friendly processes; right extraction of natural resources, renewable and non-renewable; right manufacturing, right packaging, right transportation, right buying, right use, right waste management and recycle, reuse and reduce (as figure 1). It can promote environmental conservation and ultimately lead to sustainable development. This path also needs be strengthened by other Buddhist virtues like kindness, contentment, and non-attachment to make it more effective in achieving sustainable development. 


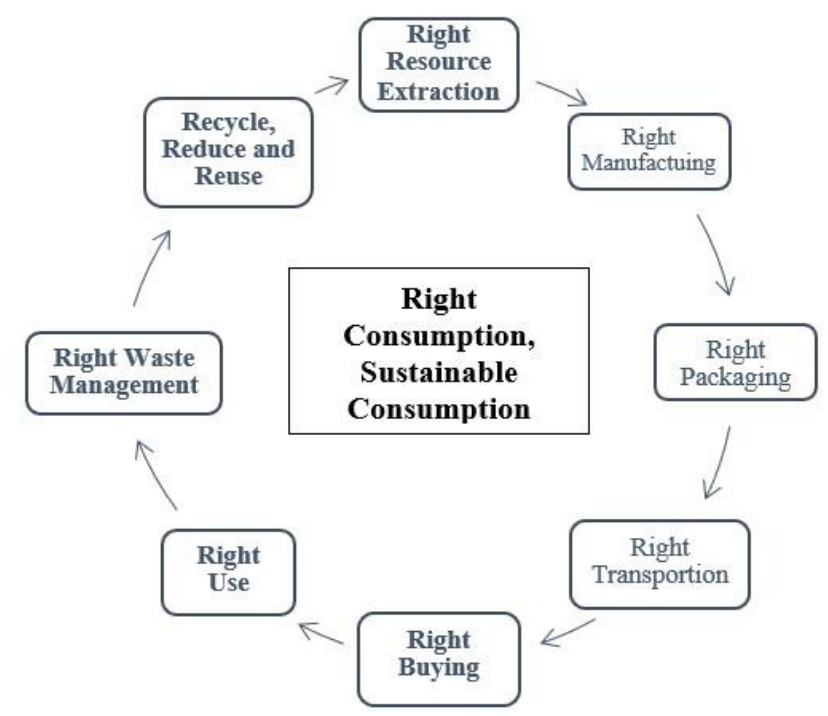

Figure 1. Aspects of Right Consumption/Sustainable Consumption

\section{Benefit Of Circular Economy}

To achieve circular economy, governments, local administrators, business sectors, manufacturers, and even consumers need to work together in the same direction in complementary patterns of production and consumption which, when combined, make sense and reinforce each other. The governments need to promote sustainable development and implementation by enforcing and monitoring responsible purchasing policies to ensure sustainable procurement. Manufactures and business sectors are required to reduce the environmental impacts of a product or service with their eco-friendly designs. They also need to search for eco-industrial synergies and collaborative economy in order to promote material efficiency and sell services related to products rather than the products themselves. Consumers also play an important role in making rational consumption choices based on social and ecological criteria and extending the duration of use through repair, reuse, repurpose, and recycle [14].

The main goals and advantages of a circular economy are concerning three dimensions: environment, economic and social. Circular economy can help protect the environment, reduce waste and the emissions of greenhouse gases, promote systematic recycling while reducing the dependence on importing raw materials, water, and energy. Circular economy also enhance the economic growth and promote the competitiveness of national companies. As a result, it creates more jobs and reduce unemployment rate and poverty as well as minimizes the social impacts of pollution and climate change.

Achieving a sustainable circular economy, the consumption and production practices need to be changed. The practices involve redesigning the products to make them last longer and can be reused, repaired and remanufactured. This can save more energy and raw materials which are going to be used in producing new products while it can help retain the functional value of the existing products. The manufacturing and business sectors have to do more with less material and consumers need to cooperate with responsible consumption.
Responsible consumption requires consumers to think carefully before making their purchase and replace the idea of purchasing with more repairing and restyling the things they have possessed. It can offer new business models for private sectors such as leasing and repairing. Thus, they will produce based on the actual demand. The new business models can create more jobs and encourage people in communities to participate in local activities and have stronger relationship [15].

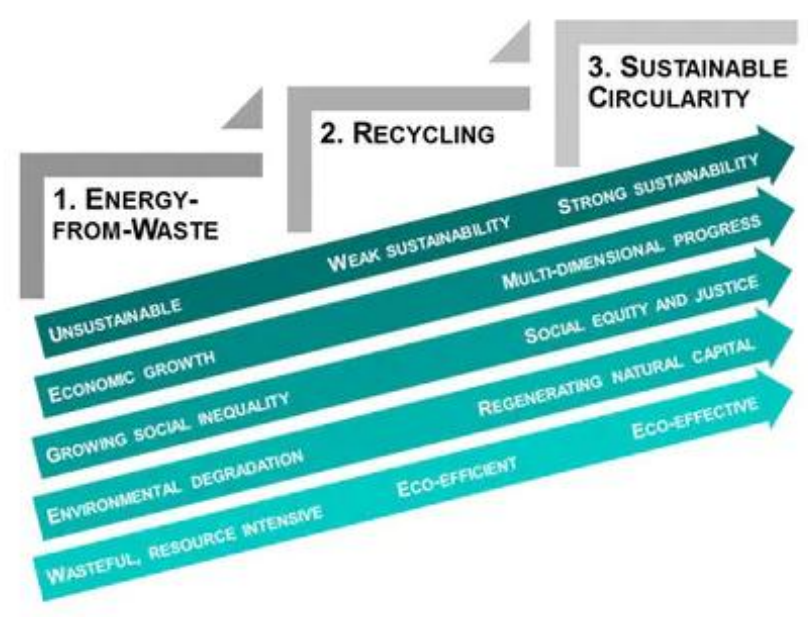

Figure 2. The Transition towards and increasingly sustainable circular economy radically changes the purpose of the economy [16]

Development in line with circular economy principles can prove for social, economic, and environmental benefits. According to Ellen MacArthur a circular economy trajectory of Chaina across five high-impact areas including the built environment, mobility, nutrition, textiles and electronics could probably save businesses and households approximately CNY 32 trillion (USD 5.1 trillion) in 2030 and CNY 70 trillion (USD 11.2 trillion) in 2040 in spending on high-quality products and services. to be beneficial for social economy, and it also has potential for large reductions in emissions of greenhouse gases $(11 \%$ by $2030,23 \%$ by $2040)$ and fine particulate matter $(10 \%$ by $2030,50 \%$ by 2040 ), and falls in traffic congestion $(36 \%$ by $2030,47 \%$ by 2040). Moreover, it can help the country reduce reliance on imported raw materials due to the lower consumption of energy and materials and greater efficiency in the mobility system [17].

Circular economy concept has been adopted in some countries as Germany, Denmark, Netherlands, Scotland, Sweden, China, and Japan, however, the implementation can be varied. For example, the CE concept in China was implemented in three layers: micro, meso, and macro while it was implemented in form of legislation, policies, and regulations in Germany and Japan [18]. The CE concept is basically developed in four stages: design, production, consumption, and waste management. Although there are differences in the implementation approaches and procedures among the countries, every country moves towards the same goal to achieve sustainable development. To be successful in the implementation of circular economy, policies and regulations need to be effectively enforced, and 
collaboration and support from all stakeholders, especially consumers, are essential.

With its aim to eliminate waste and promote continual use of resources, circular economy concept is now becoming a new model of resilient and sustainable development for developed and developing countries. It can be a potential alternative to the traditional manufacturing-led economy, especially for developing countries because it provides new strategy for industrial development and more economic opportunities. However, the pathways to circular economy for developing countries need to be different from those applied in the developed countries because their political and economic conditions are different.

The circular economy model is based on minimizing the extraction of raw materials and replacing the linear economic model with resources conservation and no waste left behind. The use of renewable energy, reduced emissions, and greater industry efficiency are also inclusive in the $\mathrm{CE}$ model. It provides us the best chance to live within the bounds of the Earth's capacity. The benefits of $\mathrm{CE}$ include less dependence on important raw materials, avoidance of environmental damage caused by resource extraction, less pollution, and more green industries and job opportunities [19].

The change to circular economy can be defined as the change in an economic system which requires practical concepts of reducing, reusing, recycling, and recovering materials to replace the traditional end-of-life concept within the 9R frameworks [20]. (figure 3) It can be operated in all sections of the economic system including consumption, production, business, government and administration at domestic, regional, national, and international levels. With its aim to achieve sustainable development, circular economy can bring about higher environmental quality, economic and social wellbeing for current and future generations.
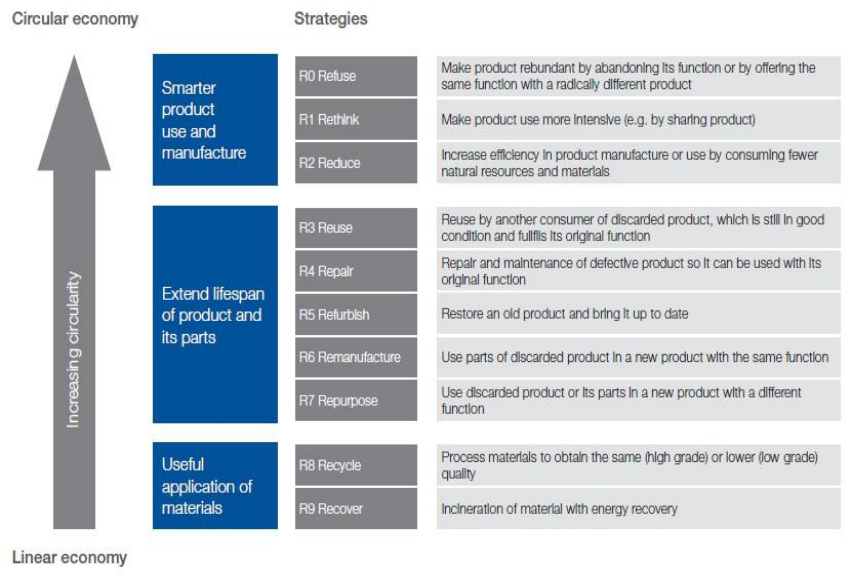

Figure 3. The 9R framework [21]

\section{How Mindful Consumption Contributes To Circular Economy}

As mentioned earlier, Responsible Consumption is an important activity encompassed in circular economy. Responsible consumption is a way of consumption that takes into account the foundations of sustainable development. According to UNEP, sustainable consumption is the use of services and related products responding to basic needs and making quality of life better while reducing the use of natural resources and toxic materials as well as the emission of waste and pollutants over the life cycle of the service [22]." Similarly, consumption according to Buddhist perspectives, mindful consumption, is the consumption in such a way of not causing a decline in the quality of one's life, not bringing distress to society and not causing degeneration in the quality of ecosystems.

Clair Brown, an economics professor at U.C. Berkeley, suggests the economic paradigm for sustainable world should highlight the interdependence, shared prosperity, and happiness rather than mainly focus on national income. Buddhist economics is based on the awareness of how our actions impact on others, society, and environment. It guides us to recognize that our lives and living are relating to others, our communities, and nature. Therefore, we can make our lives better and happier as well as promote wellbeing for future generations and for our world if we do more valuable activities instead of continuing our endless desire [23].

Buddhism offers a rational guidance to manage the conflicts between the consumerism economic system and the changes required for achieving environmental sustainability. The logic principles of Buddhism's Four Noble Truths, and the right mindfulness in the Eightfold Path can be applied with the knowledge and experience available in the present economics and environmental science as a practical framework for the successful transformation to sustainable economies. The Buddhist view of the nature of reality and path to well-being share much in common with social and intellectual development for sustainability. They can reinforce each other in the process of reducing society's metabolism and nature intervention levels, and at the same time promoting the intrinsic interconnectedness of human existence and interaction with the broader social and natural worlds [24].

Changing to mindful consumption, one needs to incorporate various changes in one's lifestyles on the basis of right understanding, which is the key principle of the Buddhist Noble Eightfold Path. To understand rightly means to understand things as they really are and not as they appear to be. A minimum degree of right understanding is necessary at the very beginning because it gives the right motivation to the other seven factors of the path and gives them the correct direction to live their lives in harmonize with the society and nature/ecosystem. No matter how well the policies and plans to circular economy are written, sustainability cannot be achieved unless consumers, the key element of the economic growth, make their choice of consumption with mindfulness. Only a mindful consumer may not be able to contribute much to circular economy, but the cumulative effect of billions of mindful consumers can make a big contribution, and the business sector will have to change their productions and services in responsive actions. (Figure 4) 


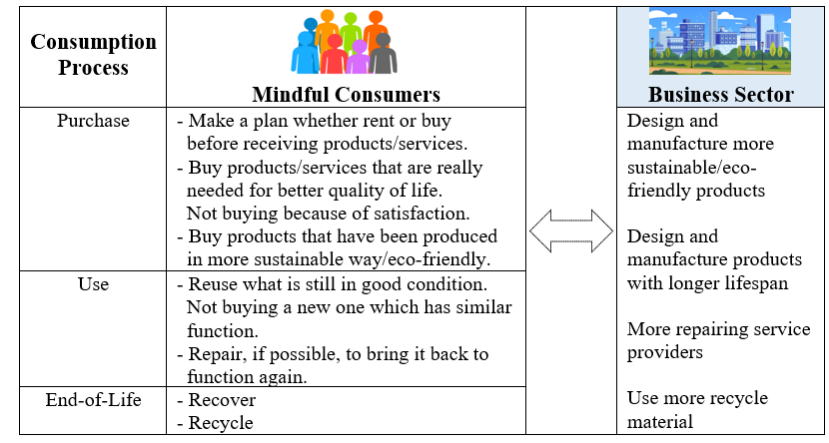

Figure 4. Contribution of Mindful Consumption to Circular Economy

\section{Conclusion}

Every resource we use in these days can cause a reduction of resource for future generations. If the current rate of consumption continues, the natural resource extraction will become double in the near future. The challenge of sustainability requires both technology and the selfrestricting of our needs that balances spiritual and material values and respects the human condition of future generations. Our world resources today are perceived and managed with an expectation of high return on investment and not treated as vulnerable common goods. Critical resources such as clean air and water require urgent action to conserve them. We will never be successful in managing such critical resources if people don't change their perspective towards the natural resources. Circular economy concept is an economic system in which resource efficiency is focused and no materials are wasted. Products are designed to maintain their function and value which allows them to be reused, recovered, and refurbished in order to extend their lifespan as well as to reduce resource extraction. The circular economy can stimulate the growth trend in recycling markets and reduce demand for primary resources, but it requires an adjustment in employment, logistics and fiscal structures in countries which are dependent on the extraction of natural resources. Circular economy can also open more opportunities for commodities and manufacturing sectors in recycling, repurposing, and reuse of the materials. It can increase overall wealth in societies, promote public wellbeing, and promote social and environmental sustainability at the same time. Ensuring sustainable consumption and production patterns has become an explicit goal of the Sustainable Development Goal (goal number 12), with the specific target of achieving sustainable management and efficient use of natural resources by 2030 .

To achieve the transition to circular economy, mindful consumption to solve the causes of wrong consumption will give an insight into the problem its consequences and will lead to the path for environmental conservation and sustainable development. Circular economy skills and knowledge are needed in different areas of public administration, industrial and business activities, and in consumption process. Therefore, education is an essential tool in providing knowledge and building understanding for the public and all stakeholders. On the way towards a circular economy, we will constantly face greater challenges that education will have to address. Lifelong learning should support the goal of making us all circular economy professionals.

\section{References}

[1] Helias, V.. (2018). Why the future of consumption is circular. Retrieved on 17 December 2020, from https://www.weforum.org/agenda/2018/01 /future-consumption-circular-economysustainable

[2] Watts, N., et al.. (2019). The 2019 report of The Lancet Countdown on health and climate change: ensuring that the health of a child born today is not defined by a changing climate. Review. Vol. 394, No. 10211.

[3] Southerton, D., Welch, D.. (2018). Transitions for Sustainable Consumption After the Paris Agreement. Retrieved on 10 December 2020, from https://stanleycenter.org/wpcontent/uploads/2019/09/CCAISustainableConsumption.pdf

[4] Warde, A.. Consumption and Theories of Practice, Journal of Consumer Culture. Retrieved on 12 December 2020, from https://metodos.files.wordpress.com/2008/ 02/consumption_practice1.pdf

[5] David M Evans. 'What Is Consumption, Where Has It Been Going, and Does It Still Matter?', UNIVERSITY OF SHEFFIELD. Retrieved on 2 December 2020, from http://eprints.whiterose.ac.uk/128406/1/W hat $\% 20 \mathrm{is} \% 20$ Consumption $\% 20 \mathrm{~V} 2 \% 20 \% 2$ 8accepted $\% 2$ C\%20pre-proof $\% 29$.pdf

[6] FAO. (2015). Regional Strategic Framework Reducing Food Losses and Waste in the Near East \& North Africa Region. Retrieved on 5 December 2020, from Http://www.fao.org/3/a-i4545e.pdf

[7] The World Bank. Global Food Loss and Waste. Retrieved on 7 December 2020, from https://datatopics.worldbank.org/what-awaste/global_food_loss_and_waste.html 
[8] K. Parajuly, et al.. (2019). Future E-Waste Scenarios, 2019. Retrieved on 28 December 2020, from https://collections.unu.edu/eserv/UNU:744 0/FUTURE_E-

WASTE_SCENARIOS_UNU_190829_lo w_screen.pdf

[9] Z. Wang, B. Zhang, D. Guan. (2016). Take responsibility for electronic-waste disposal Nature, NATURE INTERNATIONAL WEEKLY JOURNAL OF SCIENCE. Retrieved on 11 December 2020, from https://www.nature.com/news/polopoly_fs $/ 1.20345 ! / \mathrm{menu} / \mathrm{main} /$ topColumns/topLeft Column/pdf/536023a.pdf

[10] V. Forti, C. Peter Baldé, R. Kuehr, G. Bel. (2020). The Global E-waste Monitor 2020. Retrieved on 3 December 2020, from https://www.itu.int/en/ITU-

D/Environment/

Documents/Toolbox/GEM_2020_def.pdf

[11] Bhikkhu Bodhi. (2016). The Buddha's teachings on social and communal harmony, Somerville: Wisdom Publications.

[12] "Circular Economy, How to shape a sustainable future?". Retrieved on 8 December 2020, from https://solarimpulse.com/circulareconomy-solutions\#

[13] Velenturf, A. and Purnell, P.. (2020). What a sustainable circular economy would look like. Retrieved on 19 December 2020, from https://theconversation.com/what-asustainable-circular-economy-would-looklike-133808

[14] Ellen MacArthur Foundation. (2018). The Circular Economy Opportunity for Urban \& Industrial Innovation in China.

[15] Olabode Emmanuel Ogunmakinde. (2019). A Review of Circular Economy Development Models in China. Germany and Japan, Recycling Journal, Vol 4 No 27.

[16] Tabener, R.. (2019). The Benefits of a Circular Economy. Retrieved on 4 December 2020, from https://www.newcmi.com/blog/thebenefits-of-a-circular-economy

[17] Kirchherr, J., Reike, D. \& Hekkert, M.. (2017). Conceptualizing the Circular Economy: An analysis of 114 definitions. Resources, Conservation \& Recycling. Vol. 127.

[18] UNEP. (2015). Sustainable Consumption and Production: A Handbook for Policy Maker, Global Edition. Retrieved on 29 December 2020, from https://www.iges.or.jp/en/publication_doc uments/pub/bookchapter/en/3121/SCP+Ha ndbook+for+Policy+Makers_Asia+Ed_\%2 81pageView\%29.pdf

[19] Brown, C.. (2017). Buddhist Economics: An Enlightened Approach to the Dismal Science. London: Bloomsbury Press.

[20] Daniels, P.. (2017). "Buddhism and the transformation to sustainable economies", Society and Economy, Vol. 29 No.2: 155180. 